\title{
Echocardiographic partition values and prevalence of left ventricular hypertrophy in hypertensive Nigerians
}

\author{
Adewole A Adebiyi ${ }^{1}$, Okechukwu S Ogah ${ }^{* 2}$, Akinyemi Aje ${ }^{2}$, Dike B Ojji², \\ Adedeji K Adebayo $^{2}$, Olulola O Oladapo ${ }^{1}$ and Ayodele O Falase ${ }^{1}$
}

\begin{abstract}
Address: ${ }^{1}$ Division of Cardiovascular Medicine, Department of Medicine, University College Hospital, Ibadan, PMB 5116 Ibadan, Oyo State, Nigeria/Division of Cardiovascular Medicine, Department of Medicine, College of Medicine, University of Ibadan, Nigeria and ${ }^{2}$ Division of Cardiovascular Medicine, Department of Medicine, University College Hospital, Ibadan, PMB 5116 Ibadan, Oyo State, Nigeria

Email: Adewole A Adebiyi - wadebiyi@comui.edu.ng; Okechukwu S Ogah* - osogah56156@yahoo.com; Akinyemi Aje - ajeyemi@yahoo.co.uk; Dike B Ojji - dikeojji@yahoo.co.uk; Adedeji K Adebayo - akbayo53972@yahoo.com; Olulola O Oladapo - dowo@skannet.com.ng; Ayodele O Falase - aofalase@yahoo.com

* Corresponding author
\end{abstract}

Published: 29 August 2006

BMC Medical Imaging 2006, 6:10 doi:10.1 186/1471-2342-6-10
Received: 22 May 2006

Accepted: 29 August 2006

This article is available from: http://www.biomedcentral.com/I47/-2342/6/10

(c) 2006 Adebiyi et al; licensee BioMed Central Ltd.

This is an Open Access article distributed under the terms of the Creative Commons Attribution License (http://creativecommons.org/licenses/by/2.0), which permits unrestricted use, distribution, and reproduction in any medium, provided the original work is properly cited.

\begin{abstract}
Background: Left ventricular hypertrophy $(\mathrm{LVH})$ is a well known independent risk factor for cardiovascular events. It has been shown that combination of left ventricular mass (LVM) and relative wall thickness (RWT) can be used to identify different forms of left ventricular (LV) geometry. Prospective studies have shown that LV geometric patterns have prognostic implications, with the worst prognosis associated with concentric hypertrophy. The methods for the normalization or indexation of LVM have also recently been shown to confer some prognostic value especially in obese population. We sought to determine the prevalence of echocardiographic ILVH using eight different and published cut-off or threshold values in hypertensive subjects seen in a developing country's tertiary centre.
\end{abstract}

Methods: Echocardiography was performed in four hundred and eighty consecutive hypertensive subjects attending the cardiology clinic of the University college Hospital Ibadan, Nigeria over a two-year period.

Results: Complete data was obtained in 457 (95.2\%) of the 480 subjects ( $48.6 \%$ women). The prevalence of LVH ranged between 30.9-56.0\%. The highest prevalence was when LVM was indexed to the power of 2.7 with a partition value of $49.2 \mathrm{~g} / \mathrm{ht}^{2.7}$ in men and $46.7 \mathrm{~g} / \mathrm{ht}^{2.7}$ in women. The lowest prevalence was observed when LVM was indexed to body surface area (BSA) and a partition value of $125 \mathrm{~g} / \mathrm{m}^{2}$ was used for both sexes. Abnormal LV geometry was present in $61.1 \%-$ $74.0 \%$ of our subjects and commoner in women.

Conclusion: The prevalence of LVH hypertensive patients is strongly dependent on the cut-off value used to define it. Large-scale prospective study will be needed to determine the prognostic implications of the different LV geometry in native Africans. 


\section{Background}

Left ventricular hypertrophy (LVH) either diagnosed by electrocardiography or echocardiography is now well known as an independent risk factor for cardiovascular events. Echocardiographic LVH is diagnosed based on cutoff values developed from population based studies in which LV mass is indexed to body surface area (BSA), height or height raised to the power of 2.7, the allometric growth rate of the heart. Based on recent work by Koren et al [1] and Ganau et al [2], combination of LVM and relative wall thickness (RWT) can now be used to identify different forms of LV geometry. Prospective studies have shown that LV geometric patterns have prognostic implications, with the worst prognosis associated with concentric hypertrophy [3]. The methods for the normalization or indexation of $\mathrm{LV}$ mass have also recently been shown to confer some prognostic value especially in obese population $[4,5]$.

Many studies have used different partition values for left ventricular mass (LVM) in the classification of LV geometry. The purpose of this study is therefore to assess the influence of various published partition values for LVM in the diagnosis of LVH and LV geometry in native Africans.

\section{Methods}

The study was carried out at the Cardiology clinic of the University College Hospital, Ibadan, Nigeria. It was an observational cross-sectional study, which was conducted within a two-year period. Hypertensive patients were eligible for the study if they fulfilled the following criteria: no evidence valvular abnormality (aortic or mitral value disease) or congestive heart failure. Subjects with sickle cell disease, diabetes mellitus, renal failure, and ischaemic heart disease were also excluded from the study. Both treated and untreated hypertensive subjects were recruited.

All the subjects gave informed consent before they were enrolled into the study. Ethical clearance was obtained from the joint University of Ibadan and University College Hospital Ibadan ethical committee.

\section{Clinical evaluation}

Baseline clinical and demographic characteristics were obtained from the subjects. These included date of birth, age, gender, history of diabetes, and history of smoking and alcohol use. Blood pressure measurements were obtained according to standard guidelines with a mercury sphygmomanometer (Accosson London). Systolic and diastolic blood pressures were measured at Korotkoff sounds phases I and V respectively. Blood pressure was measured at the right arm three (3) times and averaged after a 5 minutes rest. Blood pressure 140/90 and above was taken as hypertension[6]. Subjects were weighed without shoes and in light clothing on a standard beam balance. Height was measured to the nearest centimetre using anthropometrical plane with subjects not putting on shoes or headgear. Body mass index (BMI) was calculated using the formula: $\mathrm{BMI}=$ Weight $(\mathrm{kg}) /($ height $)$. Body surface area (BSA) was calculated using the formula of Dubois.[7]

\section{Echocardiography}

M-mode, 2D and Doppler echocardiography were performed using a standard protocol and an ALOKA SSD echocardiography machine (Aloka Co. Ltd., Tokyo, Japan). Two dimensional guided M- mode measurements were made according to the recommendations of the American Society of Echocardiography (ASE) [8]. LV internal dimension, posterior wall thickness and interventricular septal thickness were measured at end-diastole and end-systole. Where optimal M-mode imaging could not be obtained, 2D linear measurements were obtained according to the ASE criteria [8]. Left atrial end systolic diameter was obtained from the trailing edge of the posterior aortic - anterior left atrial complex. Measurements were obtained in up to 3 cardiac cycles according to the ASE convention [8]. Two experienced physicians performed the echocardiography. In our laboratory, the intra-observer concordance correlation coefficient ranged from 0.76 to 0.98 while that of the inter-observer concordance ranged from 0.82 to $0.96[9]$

\section{Calculation of derived variables}

Left ventricular mass was calculated using the formula of Devereux and Reichek.[10] This has been shown to yield LVM closely related to autopsy measurements $(\mathrm{r}=$ $0.90)[11]$ and has good interobserver reproducibility $(\rho=$ 0.93 ) in one study[12]. Relative wall thickness (RWT) was derived from $2 \mathrm{X}$ posterior wall thickness/LV internal diameter. Increased RWT was considered to be present when RWT exceeded 0.43 . This represents the $97.5^{\text {th }}$ percentile in normal subjects [13].

We assessed left ventricular hypertrophy using various published partition values.

Partition values for LVM normalized for BSA were:

$125 \mathrm{~g} / \mathrm{m}^{2}$ for both men and women[1],

$116 \mathrm{~g} / \mathrm{m}^{2}$ for men and $104 \mathrm{~g} / \mathrm{m}^{2}$ for women[14],

$125 / \mathrm{m}^{2}$ for men and $110 \mathrm{~g} / \mathrm{m}^{2}$ for women[15],

$131 \mathrm{~g} / \mathrm{m}^{2}$ for men and $100 \mathrm{~g} / \mathrm{m}^{2}$ for women[16].

Partition values for LVM indexed for height were: 
$126 \mathrm{~g} / \mathrm{m}$ for men and $105 \mathrm{~g} / \mathrm{m}$ for women[17]

$143 \mathrm{~g} / \mathrm{m}$ for men and $102 \mathrm{~g} / \mathrm{m}$ for women[16],

Values for LVM raised to the allometric growth rate of 2.7 were:

$51 \mathrm{~g} / \mathrm{m}^{2.7}$ for both men and women[17]

$49.2 \mathrm{~g} / \mathrm{m}^{2.7}$ for men and $46.7 \mathrm{~g} / \mathrm{m}^{2.7}$ for women[17]

Left ventricular geometric was defined as follows: Normal geometry, when LVMI and RWT were normal; Concentric remodeling, when LVMI was normal and RWT increased; Eccentric hypertrophy, when LVMI was increased but normal RWT; and Concentric hypertrophy, when both LVMI and RWT were increased [2].

\section{Statistical analysis}

SPSS version 11.0 software (SPSS, Chicago, IL, USA) was used in the analysis of the data. Continuous variables were expressed as mean $\pm \mathrm{SD}$ while categorical variables were expressed as counts (percentages). Normality of continuous variables was assessed using the KolmogorovSmirnov statistics. Comparison between two groups was assessed by the Students t- test for independent variables while the $\chi^{2}$ analysis was used to compare proportions. A 2-tailed p-value of 0.05 was assumed statistically significant.

\section{Results}

\section{Clinical characteristics}

The clinical characteristic of our study subjects is as shown in Table 1. A total of four hundred and eighty hypertensive subjects who met the inclusion criteria were recruited for the study. Twenty three (23) subjects were dropped from the final analysis because of incomplete data or inadequate echocardiogram. Four hundred and fifty seven subjects were included in the analysis $(95.2 \%)$. These were two hundred and thirty five (235) men and two hundred and twenty two (222) women constituting 51.4\% and $48.6 \%$ respectively. The mean ages for men and women were similar $(56.0 \pm 13.0$ vs $55.5 \pm 13.5, \mathrm{p}=$ 0.672 ). The men were taller and had a greater body surface area than the women $(\mathrm{P}<0.0001)$. Clinic blood pressures were similar in both sexes.

\section{Echocardiographic measurements}

Table 2 shows the echocardiographic measurements in the subjects. The echocardiographic LV parameters were generally higher in men than in women except for the indexes of LV systolic function.

Table 3 depicts the prevalence of left ventricular hypertrophy and abnormal LV geometry in the hypertensive sub- jects. The prevalence of left ventricular hypertrophy based on LVM above the threshold value ranged between 30.9\% and $56 \%$. The lowest prevalence is when LVM was indexed to BSA and a partition value of $125 \mathrm{~g} / \mathrm{m}^{2}$ was used for both sexes. Highest prevalence occurred when LVM was indexed to height raised to the power of 2.7 and partition value of $49.2 \mathrm{~g} / \mathrm{ht}^{2.7}$ in men and $46.7 \mathrm{~g} / \mathrm{ht} 2.7 \mathrm{in}$ women. The prevalence of abnormal LV geometry ranged from $61.1 \%$ to $74 \%$.

Table 4 shows the distribution of LV Geometry according to gender. Abnormal LV geometry is significantly higher in women than men except when LVM was indexed to height ${ }^{2.7}$ with a partition value of $51 \mathrm{~g} /$ height $^{2.7}$ for both sexes.

\section{Discussion}

It is now well established that LVH either determined by electrocardiography or echocardiography is a strong predictor of poor prognosis in cardiovascular disorders independent of traditional risk factors. Various authors have used different partition values to define increased LVM. This includes BSA [18], BSA raised to the power of 1.5; height, height raised to the power of 2.0, 2.13, 2.7[17] and 3.0. Furthermore, combination of indexed LVM and RWT has been used to define geometry.

This study is the first to look at the impact of various cutoff values for LVM on the prevalence of LVH and abnormal LV geometry in hypertensive native Africans.

Our study shows that the prevalence of LVH ranges between $30.9-56.0 \%$. We also observed that the highest prevalence was when LVM was indexed to the power of 2.7 with a partition value of $49.2 \mathrm{~g} / \mathrm{ht}^{2.7}$ in men and 46.7 $\mathrm{g} / \mathrm{ht}^{2.7}$ in women. The lowest prevalence was observed when LVM was indexed to BSA and a partition value of $125 \mathrm{~g} / \mathrm{m}^{2}$ was used for both sexes. We also report that abnormal LV geometry is present in $61.1 \%-74.0 \%$ of our subjects. Eccentric LV geometry was the commonest abnormal geometry in our hypertensive population (17.5-30.4\%) while concentric LV geometry was present in $3.3-25.6 \%$ of the subjects. Normal geometry was seen in $26-38.9 \%$. Abnormal geometry was more common in women in all the partition values.

Our finding is similar to those of other workers. Wachtell and his colleagues [19] in the LIFE multi-centre study group studied 941 stage I-III hypertensive subjects. They reported a $42-78 \%$ prevalence of $\mathrm{LVH}$ and $63-86 \%$ prevalence of abnormal LV geometry. Fifteen to forty percent $(15-40 \%)$ of their subjects had normal geometry. Eccentric LV geometry was also the commonest abnormal LV geometry in their study. 
Table I: Baseline clinical and demographic characteristics

\begin{tabular}{|c|c|c|c|c|}
\hline Parameter & $\begin{array}{l}\text { All Subjects } \\
N=457\end{array}$ & $\begin{array}{l}\text { Men } \\
N=235(5 I .4 \%)\end{array}$ & $\begin{array}{l}\text { Women } \\
N=222(48.6 \%)\end{array}$ & P-value \\
\hline Age (yrs) & $55.8 \pm 13.3$ & $56.0 \pm 13.0$ & $55.5 \pm 13.5$ & 0.672 \\
\hline Weight (kg) & $73.1 \pm 13.7$ & $71.4 \pm 13.5$ & $74.8 \pm 13.7$ & 0.009 \\
\hline Height $(\mathrm{cm})$ & $164.3 \pm 8.3$ & $169.1 \pm 6.9$ & $159.3 \pm 6.5$ & $<0.0001$ \\
\hline Body Mass Index (kg/m²) & $27.1 \pm 4.8$ & $26.1 \pm 4.4$ & $28.1 \pm 5.0$ & $<0.0001$ \\
\hline Body Surface Area $\left(\mathrm{m}^{2}\right)$ & $1.79 \pm 0.18$ & $1.85 \pm 0.17$ & $1.74 \pm 0.16$ & $<0.0001$ \\
\hline Heart Rate (beats/min) & $80.4 \pm 16.7$ & $80.2 \pm 17.3$ & $80.6 \pm 16.1$ & 0.774 \\
\hline Systolic Blood Pressure (mmHg) & $142.7 \pm 20.8$ & $142.8 \pm 21.0$ & $142.7 \pm 20.7$ & 0.986 \\
\hline Diastolic Blood Pressure (mmHg) & $88.3 \pm 12.9$ & $88.1 \pm 12.8$ & $88.5 \pm 13.0$ & $0.7 \mid 4$ \\
\hline Pulse Pressure $(\mathrm{mmHg})$ & $54.3 \pm 16.8$ & $54.7 \pm 17.8$ & $54.0 \pm 15.7$ & 0.648 \\
\hline Mean Arterial Pressure $(\mathrm{mmHg})$ & $106.2 \pm 14.8$ & $106.3 \pm 13.6$ & $106.1 \pm 15.9$ & 0.887 \\
\hline \%Overweight & $27.8 \%$ & $19.1 \%$ & $36.9 \%$ & $<0.0001$ \\
\hline
\end{tabular}

In a cross-sectional study, Coca et al studied 946 hypertensive subjects recruited randomly from thirty nine (39) primary health care centres in Spain. They reported a 59.2$72.7 \%$ prevalence of LVH depending on the criteria used. They also noted that the prevalence of LVH was higher in men using the Framingham criteria but higher in women using de Simone et al criteria. Eccentric LVH was the commonest abnormal criteria in their study (51.3-54.1\%) independent of the criteria used. Normal geometry was seen in $20.8-29.7 \%$ of their subjects. Overall, 70.3$79.2 \%$ of their hypertensive subjects had abnormal geometry.

Cuspidi and his co-workers[20], using six different echocardiographic criteria, studied 611 consecutive hypertensive subjects in Italy. The prevalence of LVH in their study was $18.6-42.7 \%$. Eccentric LV geometry was commonest and abnormal LV geometry was more common in women than the men. They also observed that LVM correlated positively well with BSA, height, and height ${ }^{2.7}$ and carotid intima-media thickness.
Three groups studied the influence of different partition values on the prevalence of LVH in newly diagnosed untreated hypertensive subjects.

In the study of 165 untreated essential hypertensive subjects by Ganau et al[2], 52\% of their subjects had normal geometry, $13 \%$ had concentric remodeling, $27 \%$ had eccentric hypertrophy while only $8 \%$ had the "typical" hypertensive left ventricular hypertrophy. Furthermore, they documented that systemic hemodynamics paralleled ventricular geometry, with the highest peripheral resistance in the groups with concentric remodeling and hypertrophy, whereas cardiac index was super-normal in those with eccentric hypertrophy and low normal in patients with concentric remodeling[2].

Gosse et al[21] studied 363 untreated patients using three partition values. They reported the prevalence of $\mathrm{LVH}$ as $48.2-50.4 \%$. The authors concluded that a cut-off value of $53 \mathrm{~g} / \mathrm{m}^{2.7}$ in men and $47 \mathrm{~g} / \mathrm{m}^{2.7}$ in women corresponded to a cardiovascular risk indicated by daytime systolic BP

Table 2: Echocardiographic parameters

\begin{tabular}{lllll}
\hline Parameter & $\begin{array}{l}\text { All Subjects } \\
\mathbf{N}=\mathbf{4 5 7}\end{array}$ & $\begin{array}{l}\text { Men } \\
\mathbf{N}=\mathbf{2 3 5}\end{array}$ & $\begin{array}{l}\text { Women } \\
\mathbf{N}=\mathbf{2 2 2}\end{array}$ & P-value \\
\hline Aorta $(\mathrm{cm})$ & $2.90 \pm(0.43)$ & $3.06 \pm 0.42$ & $2.74 \pm 0.37$ & $<0.0001$ \\
Left Atrium $(\mathrm{cm})$ & $3.51 \pm(0.65)$ & $3.59 \pm 0.67$ & $3.42 \pm 0.62$ & $1.00 \pm 0.18$ \\
IVSTd $(\mathrm{cm})$ & $1.04 \pm(0.18)$ & $1.08 \pm 0.17$ & $0.98 \pm 0.20$ & $<0.004$ \\
PWTd (cm) & $1.00 \pm(0.19)$ & $1.01 \pm(0.17)$ & $4.54 \pm 0.75$ & 0.001 \\
LVEDD (cm) & $4.82 \pm 0.91$ & $5.08 \pm 0.96$ & $3.01 \pm 0.77$ & 0.0001 \\
LVESD (cm) & $3.26 \pm(0.95)$ & $3.49 \pm 1.04$ & $34.4 \pm 8.13$ & 0.001 \\
FS (\%) & $33.5 \pm 8.1$ & $32.7 \pm 8.07$ & $70.3 \pm 10.4$ & 0.032 \\
EF (\%) & $69.4 \pm 10.7$ & $68.4 \pm 10.9$ & & 0.059 \\
\hline
\end{tabular}

IVSTd= interventricular Septal Thickness in Diastole, PWTd= Posterior Wall Thickness in Diastole, LVEDD= Left Ventricular End-Diastolic Diameter, LVESD= Left Ventricular End-Systolic Diameter, FS= Fractional Shortening, EF= Ejection Fraction 
Table 3: LV geometric patterns according to partition value

\begin{tabular}{|c|c|c|c|c|c|c|c|}
\hline $\begin{array}{l}\text { PARTITION } \\
\text { VALUE }\end{array}$ & LVH/NO LVH & \%LVM & $\begin{array}{l}\text { NORMAL } \\
\text { GEOMETRY (i) }\end{array}$ & $\begin{array}{l}\text { CONCENTRIC } \\
\text { REMODELLING (ii) }\end{array}$ & $\begin{array}{l}\text { ECCENTRIC } \\
\text { HYPERTROPHY } \\
\text { (iii) }\end{array}$ & $\begin{array}{l}\text { CONCENTRIC } \\
\text { HYPERTROPHY } \\
\text { (iv) }\end{array}$ & $\begin{array}{l}\text { \%ABNORMAL } \\
\text { LV-GEOMETRY } \\
(\mathrm{ii}+\mathrm{iii}+\mathrm{iv})\end{array}$ \\
\hline $\begin{array}{l}\text { LVM/BSA } \\
M / F=116 / 104\end{array}$ & $221 / 236$ & 48.4 & $133(29.1 \%)$ & $103(22.5 \%)$ & $125(27.4 \%)$ & $96(21.0 \%)$ & 70.9 \\
\hline $\begin{array}{l}\text { LVM/BSA } \\
M / F=125 / 125\end{array}$ & $14 \mid / 316$ & 50.3 & $178(38.9 \%)$ & $138(30.2 \%)$ & $80(17.5 \%)$ & $61(13.4 \%)$ & 73.5 \\
\hline $\begin{array}{l}\text { LVM/BSA } \\
M / F=125 / 110\end{array}$ & $180 / 277$ & 56 & $159(34.9 \%)$ & II8(25.8\%) & $99(21.7 \%)$ & $81(17.6 \%)$ & 74 \\
\hline $\begin{array}{l}\text { LVM/BSA } \\
\mathrm{M} / \mathrm{F}=131 / 110\end{array}$ & $208 / 249$ & 30.9 & $138(30.2 \%)$ & III(24.3\%) & $120(26.3 \%)$ & $88(19.1 \%)$ & 61.1 \\
\hline $\begin{array}{l}\mathrm{LVM} / \mathrm{HT} \\
\mathrm{M} / \mathrm{F}=143 / 102\end{array}$ & $230 / 227$ & 39.4 & $121(26.5 \%)$ & $106(23.2 \%)$ & $137(30.0 \%)$ & $93(20.3 \%)$ & 65.2 \\
\hline $\begin{array}{l}\mathrm{LVM} / \mathrm{HT} \\
\mathrm{M} / \mathrm{F}=126 / 105\end{array}$ & $242 / 215$ & 45.5 & $120(26.2 \%)$ & $95(20.8 \%)$ & $138(30.2 \%)$ & $104(22.8 \%)$ & 69.8 \\
\hline $\begin{array}{l}\text { LVM/HT2.7 } \\
\mathrm{M} / \mathrm{F}=49.2 / 46.7\end{array}$ & $256 / 201$ & 53 & $119(26.1 \%)$ & $82(17.9 \%)$ & $139(30.4 \%)$ & $117(25.6 \%)$ & 73.7 \\
\hline $\begin{array}{l}\mathrm{LVM} / \mathrm{HTT}^{2.7} \\
\mathrm{M} / \mathrm{F}=5 \mathrm{I} / 5 \mathrm{I}\end{array}$ & $211 / 246$ & 46.2 & $140(30.6 \%)$ & $106(23.2 \%)$ & $118(25.8 \%)$ & $93(20.4 \%)$ & 69.4 \\
\hline
\end{tabular}

LV = Left Ventricular, LVM = Increased Left Ventricular Mass, BSA = Body Surface Area, HT = Height, M/F = Male/Female.

$>=135 \mathrm{mmHg}$. Another study reported a prevalence of 9$25 \%$ in newly diagnosed hypertensive subjects [22].

Similar to the observation of Wachtell et al, most of the criteria yielded unequal distribution of abnormal LV geometry between men and women in our study. But unlike their finding (where four criteria gave similar distribution in men and women), only one criterion gave similar distribution in men and women (LVM/ht ${ }^{2.7}$ with a partition value of $51 \mathrm{~g} / \mathrm{ht}^{2.7}$ in both men and women). All the other criteria gave higher prevalence of abnormal LV geometry in women than in men. This is similar to the observations by Wachtell et al[19]. The most plausible reason for this is that the men in this study generally had larger BSA and were taller than their female counterparts. The later are however heavier and have larger BMI as noted in the baseline characteristics of the subjects in this study and in our previous reports[9].

Two recent publications have compared the prognostic implications of different normalization for LVH. Report from the Strong Heart Study group showed that the presence of LVH identified by LV mass normalized for height to allometric powers is associated with higher incident cardiovascular events than is LVH detected by normalization for body surface area[5]. In the second study con-

Table 4: Distribution of LV geometry according to gender

\begin{tabular}{|c|c|c|c|c|c|}
\hline Partition value & $\begin{array}{l}\text { Normal geometry } \\
\text { M/F }\end{array}$ & $\begin{array}{l}\text { Concentric remodeling } \\
\mathrm{M} / \mathrm{F}\end{array}$ & $\begin{array}{l}\text { Eccentric Hypertrophy } \\
M / F\end{array}$ & $\begin{array}{l}\text { Concentric hypertrophy } \\
\text { M/F }\end{array}$ & $\mathrm{P}$-value \\
\hline $\begin{array}{l}\text { LVM/BSA } \\
M / F=116 / 104\end{array}$ & $84 / 49$ & $73 / 30$ & $34 / 91$ & $31 / 65$ & $<0.0001$ \\
\hline $\begin{array}{l}\text { LVM/BSA } \\
M / F=125 / 125\end{array}$ & $94 / 84$ & $83 / 55$ & $24 / 56$ & $21 / 40$ & $<0.0001$ \\
\hline $\begin{array}{l}\text { LVM/BSA } \\
M / F=125 / 110\end{array}$ & $94 / 65$ & $83 / 35$ & $24 / 75$ & $21 / 60$ & $<0.0001$ \\
\hline $\begin{array}{l}\text { LVM/BSA } \\
M / F=131 / 110\end{array}$ & $95 / 43$ & $85 / 26$ & $23 / 97$ & $19 / 69$ & $<0.0001$ \\
\hline $\begin{array}{l}\mathrm{LVM} / \mathrm{HT} \\
\mathrm{M} / \mathrm{F}=143 / 102\end{array}$ & $90 / 31$ & $87 / 19$ & $28 / 109$ & $17 / 76$ & $<0.0001$ \\
\hline $\begin{array}{l}\mathrm{LVM} / \mathrm{HT} \\
\mathrm{M} / \mathrm{F}=126 / 105\end{array}$ & $85 / 35$ & $73 / 22$ & $33 / 105$ & $31 / 73$ & $<0.0001$ \\
\hline $\begin{array}{l}\mathrm{LVM} / \mathrm{HT}^{2} .7 \\
\mathrm{M} / \mathrm{F}=49.2 / 46.7\end{array}$ & $64 / 55$ & $54 / 28$ & $54 / 85$ & $50 / 67$ & 0.0011 \\
\hline $\begin{array}{l}\mathrm{LVM} / \mathrm{HT}^{2} .7 \\
\mathrm{M} / \mathrm{F}=5 \mathrm{I} / 5 \mathrm{I}\end{array}$ & 69/7I & $58 / 48$ & $49 / 69$ & $46 / 47$ & 0.261 \\
\hline
\end{tabular}

LV = Left Ventricular, LVM = Left Ventricular Mass, BSA = Body Surface Area, HT = Height, M/F = Male/Female 
ducted in a population of hypertensive subjects with low prevalence of obesity, population risk attributable to LV hypertrophy was similar for height as well as body surface area based partition values [4]. Large scale prospective study similar to these will surely be required in defining the prognostic implications of different LV geometry in native Africans.

\section{Limitations}

The subjects used for this single centre cross-sectional study were unselected in terms of whether on treatment or not. Similar study will therefore be necessary in newly diagnosed untreated hypertensive Nigerians.

\section{Conclusion}

LVH by echocardiography is present in $30.9-56.0 \%$ of hypertensive Nigerian seen in tertiary health care setting. Abnormal LV geometry is found in $61.1-74.0 \%$ of the subjects. Eccentric LV geometry is the commonest abnormal LV geometry in our subjects. Abnormal LV geometry is commoner in women and unevenly distributed in men and women except when the partition value of $51 \mathrm{~g} / \mathrm{ht}^{2.7}$ was used for both gender.

Partition values are strongly population dependent since they are derived from reference normal subjects. Different methods of indexation lead to different prevalence of LVH because the LV mass is looked at from different point of view. For example indexation to BSA offsets the independent impact of obesity on LV mass while indexation for height (especially when indexed to height raised to the power of 2.7) is useful in the definition of "genetically determined" LV mass.

Large scale prospective study will be needed to determine the prognostic implications of the different LV geometry in native Africans. We also intend to define which method of indexation is more reliable in our population through future prospective studies.

\section{Competing interests}

The author(s) declare that they have no competing interests.

\section{Authors' contributions}

AAA, OSO and AA conceived of the study and participated in the study design. OSO drafted the manuscript, AAA and OSO carried out the statistical analysis. OOO took part in the study design and study conception. DBO and AKA participated in the study design and data acquisition. AOF conceived of the study and participated in the study design. All authors read and approved the final manuscript.

\section{Acknowledgements}

We acknowledge Mrs. K.A Ogunrinde, A.O. Adegbola, O.B. Adubi and Miss H.M. Elutifaju of the ECG/ECHO Unit of University College Hospital,

Ibadan for their invaluable assistance.

Source of funding: None

\section{References}

I. Koren MJ, Devereux RB, Casale PN, Savage DD, Laragh JH: Relation of left ventricular mass and geometry to morbidity and mortality in uncomplicated essential hypertension. Ann Intern Med | 991, I | 4:342.

2. Ganau A, Devereux RB, Roman MJ, de Simone G, Pickering TG, Saba PS, Vargiu P, Simongini I, Laragh JH: Patterns of left ventricular hypertrophy and geometric remodeling in essential hypertension. J Am Coll Cardiol 1992, 19(7): I550-1558.

3. Verdecchia P, Schillaci G, Borgioni C, Ciucci A, Gattobigio R, Zampi I, Santucci A, Santucci C, Reboldi G, Porcellati C: Prognostic value of left ventricular mass and geometry in systemic hypertension with left ventricular hypertrophy. Am J Cardiol 1996, 78(2): 197-202.

4. de Simone G, Devereux RB, Maggioni AP, Gorini M, de Divitiis O, Verdecchia $P$ : Different normalizations for body size and population attributable risk of left ventricular hypertrophy: the MAVI study. Am J Hypertens 2005, I 8(1 0): I288-। 293.

5. de Simone G, Kizer JR, Chinali M, Roman MJ, Bella JN, Best LG, Lee ET, Devereux RB: Normalization for body size and populationattributable risk of left ventricular hypertrophy: the Strong Heart Study. Am J Hypertens 2005, I 8(2 Pt I): $|9|-196$.

6. World Health Organisation-International Society of Hypertension guidelines for the management of hypertension. Guideline Subcommitee. J Hypertens 1999, 17:15I-183.

7. Dubois D, Dubois EF: $\mathbf{A}$ formula to estimate the approximate surface area if height and weight be known. Arch Intern Med 1916, 17:863-87|.

8. Sahn DJ, DeMaria A, Kisslo J, Weyman A: Recommendations regarding Quantitation in M-mode Echocardiography. Results of a survey of Echocardiographic measurements. Circulation 1978, 56:1072-1083.

9. Adebiyi AA, AJE A, Ogah OS, Ojji DB, Dada A, Oladapo O, Falase AO: Correlates of left atrial size in Nigerian hypertensives. Cardiovasc J South Afr 2005, 16(3):201-204.

10. Devereux RB, Reichek N: Echocardiographic determination of LVM in man:anatomic validation of the method. Circulation 1977, 5:613-618.

II. Devereux RB, Alonso DR, Lutas EM, Gottlieb GJ, Campo E, Sachs I, Reichek N: Echocardiographic assessment of left ventricular hypertrophy:comparison to necropsy findings. Am j Cardiol 1986, 57:450-458.

12. Palmieri V, Dahlof B, De Quattro V, Sharpe N, Bella JN, de Simone G, Paranicas M, Fishman D, Devereux RB: Reliability of echocardiographic assessment of left ventricular structure and function. The PRESERVE study. J Am Coll Cardiol 1999, 34:1625-1632.

13. Roman MJ, Pickering TG, Schwartz JE, Pini R, Devereux RB: Association of carotid atherosclerosis and left ventricular hypertrophy. J Am Coll Cardiol I 995, 25(I):83-90.

14. Devereux RB, Dahlof B, Levy D, Pfeffer MA: Comparison of enalapril versus nifedipine to decrease left ventricular hypertrophy in systemic hypertension (the PRESERVE trial). Am J Cardiol 1996, 78(I):6I-65.

15. Hammond IW, Devereux RB, Alderman MH, Lutas EM, Spitzer MC, Crowley JS, Laragh JH: The prevalence and correlates of echocardiographic left ventricular hypertrophy among employed patients with uncomplicated hypertension. J Am Coll Cardiol 1986, 7(3):639-650.

16. Levy D, Savage DD, Garrison RJ, Anderson KM, Kannel WB, Castelli WP: Echocardiographic criteria for left ventricular hypertrophy: the Framingham Heart Study. Am J Cardiol 1987, 59(9):956-960.

17. de Simone G, Devereux RB, Daniels SR, Koren MJ, Meyer RA, Laragh $J \mathrm{H}$ : Effect of growth on variability of left ventricular mass: assessment of allometric signals in adults and children and their capacity to predict cardiovascular risk. J Am Coll Cardiol 1995, 25(5): 1056-1062. 
18. Ghali JK, Liao Y, Simmons B, Castaner A, Cao G, Cooper RS: The prognostic role of left ventricular hypertrophy in patients with or without coronary artery disease. Ann Intern Med 1992, I I 7( I 0):83|-836

19. Wachtell K, Bella JN, Liebson PR, Gerdts E, Dahlof B, Aalto T, Roman MJ, Papademetriou V, Ibsen H, Rokkedal J, et al.: Impact of different partition values on prevalences of left ventricular hypertrophy and concentric geometry in a large hypertensive population : the LIFE study. Hypertension 2000, 35(I Pt I):6-I2.

20. Cuspidi C, Lonati L, Macca G, Sampieri L, Fusi V, Michev I, Severgnini $B$, Salerno M, Magrini F, Zanchetti A: Prevalence of left ventricular hypertrophy and carotid thickening in a large selected hypertensive population: impact of different echocardiographic and ultrasonographic diagnostic criteria. Blood Press 200I, I0(3): I 42-149.

21. Gosse P, Jullien V, Jarnier P, Lemetayer P, Clementy J: Echocardiographic definition of left ventricular hypertrophy in the hypertensive: which method of indexation of left ventricular mass? J Hum Hypertens 1999, I3(8):505-509.

22. Cuspidi C, Macca G, Sampieri L, Michev I, Fusi V, Salerno M, Severgnini B, Corti C, Magrini F, Zanchetti A: Influence of different echocardiographic criteria for detection of left ventricular hypertrophy on cardiovascular risk stratification in recently diagnosed essential hypertensives. J Hum Hypertens 200I, I 5(9):619-625.

\section{Pre-publication history}

The pre-publication history for this paper can be accessed here:

http://www.biomedcentral.com/1471-2342/6/10/prepub

Publish with Biomed Central and every scientist can read your work free of charge

"BioMed Central will be the most significant development for disseminating the results of biomedical research in our lifetime. "

Sir Paul Nurse, Cancer Research UK

Your research papers will be:

- available free of charge to the entire biomedical community

- peer reviewed and published immediately upon acceptance

- cited in PubMed and archived on PubMed Central

- yours - you keep the copyright

Submit your manuscript here:

http://www.biomedcentral.com/info/publishing_adv.asp 